Metelitsa A, Starchenko V. Influence of intellectual educational tasks on actualization of needs in physical culture knowledge and physical culture thinking of students. Theory and Methods of Physical education and sports. 2019; 1: 71-78

DOI:10.32652/ tmfvs.2019.1.71-78
Метелица А., Старченко В. Влияние интеллектуальных учебных заданий на актуализацию потребностей в фризкультурных знаниях и фризкультурном мышлении учащихся. Теорія і методика фрізичного виховання і спорту. 2019.1: 71-78 DOI:10.32652/tmfvs.2019.1.71-78

\title{
ВЛИЯНИЕ ИНТЕЛЛЕКТУАЛЬНЫХ УЧЕБНЫХ ЗАДАНИЙ НА АКТУАЛИЗАЦИЮ ПОТРЕБНОСТЕЙ В ФИЗКУЛЬТУРНЫХ ЗНАНИЯХ И ФИЗКУЛЬТУРНОМ МЫШЛЕНИИ УЧАЩИХСЯ
}

\section{Александр Метелица, Владимир Старченко}

Гомельский государственный университет имени Франциска Скорины, Гомель, Республика Беларусь

Анотація. Стаття присвячена проблемі актуалізації потреб у фрізкультурних знаннях і фрізкультурному мисленні учнів другого і третього ступенів загальної середньої освіти. Мета. Експериментально апробувати ефективність застосування інтелектуальних навчальних завдань (використовуваних у рамках педагогічної техноло2ії), спрямованих на фрормування потреб у фрізкультурних знаннях і фрізкультурному мисленні учнів. Методи. Анкетування, що фрормує педагогічний експеримент, методи математичної статистики. Результати. У дослідженні брали участь учні I-IV курсів ДУО «Спеціалізований ліцей при Університеті цивільного захисту МНС Республіки Білорусь» у кількості 194 чоловік. У статті представлені деякі інтелектуальні учбові завдання, використовувані для фрормування потреб у фрізкультурних знаннях і фрізкультурному мисленні учнів. Виявлено, що за період проведення формуючого педагогічного експерименту під впливом інтелектуальних навчальних завдань в експериментальній групі статистично значуще підвищилася міра актуалізації потреб у фрізкультурних знаннях і фрізкультурному мисленні, тоді як в контрольній групі статистично значущих позитивних змін виявлено не було. Результати, отримані за період проведення формуючого експерименту, свідчать про ефективність використання у рамках педагогічної технології інтелектуальних навчальних завдань, спрямованих на фрормування потреб у фрізкультурних знаннях і фрізкультурному мисленні учнів другого і третього рівня загальної середньої освіти. Формуванню потреб у фрізкультурних знаннях і фрізкультурному мисленні сприяє дотримання таких умов: включення учнів в інтелектуальну фрізкультурну діяльність, надання їм різноманітних інтелектуальних навчальних завдань, забезпечення взаємозв'язку інтелектуальних навчальних завдань з руховими завданнями, наявність якісної демонстрації зразків фрізкультурних знань і фрізкультурного мислення, використання системи зовнішньої мотивації до навчальної діяльності.

Ключові слова: мотиваційно-ціннісна сфрера, фрізкультурні потреби, інтелектуальні навчальні завдання.

\section{Aleksandr Metelitsa, Vladimir Starchenko}

\section{INFLUENCE OF INTELLECTUAL EDUCATIONAL TASKS ON ACTUALIZATION OF NEEDS IN PHYSICAL CULTURE KNOWLEDGE AND PHYSICAL CULTURE THINKING OF STUDENTS}

Abstract. The article deals with the problem of actualization of needs in physical culture knowledge and thinking of students of the second and third stages of general secondary education. Objective. To test experimentally the effectiveness of the use of intellectual educational tasks (used within the framework of pedagogical technology), aimed at forming needs in physical culture knowledge and thinking of students. Methods. A questionnaire forming a pedagogical experiment, methods of mathematical statistics. Results. The study involved 194 students of I-IV courses of DUO "Specialized Lyceum at the University of Civil Protection of the Ministry of Emergencies of the Republic of Belarus». The article presents some intellectual educational tasks that were used to form the needs in physical culture knowledge and thinking of students. It was revealed that during the period of the formation pedagogical experiment under the influence of intellectual educational tasks in the experimental group, the measure of actualization of needs in physical culture knowledge and thinking has increased statistically significantly, whereas in the control group no statistically significant positive changes have been observed. The results obtained during the period of the formation experiment, are indicative of the effectiveness of the use within the frames of pedagogical technology of intellectual educational tasks, aimed at forming the needs for physical culture knowledge and thinking of pupils of the second and third levels of general secondary education. The formation of needs for physical culture knowledge and thinking is contributed by the following conditions: inclusion of students in intellectual physical culture activities, providing them with various intellectual learning tasks, ensuring the interconnection of intellectual learning tasks with motor ones, the presence of high-quality demonstration of samples of physical culture knowledge and thinking, the use of the system of external motivation for educational activities.

Keywords: motivation-value sphere, physical culture needs, intellectual educational tasks.

Введение. Потребностно-мотивационно-ценностная сфера (ПМЦС) является одним из важнейших элементов физической культуры человека, поскольку уровень ее сформированности опреде- ляет степень реальной включенности человека в физкультурно-спортивную деятельность. Отсюда следует, что в процессе физического воспитания формированию ПМЦС физической культуры уча- 
щихся нужно уделять большое внимание. На важность ее формирования указывают многие ученые $[4,6,7]$.

Анализ научно-методической литературы показал, что среди ученых нет единого мнения относительно структуры и содержания ПМЦС физической культуры человека. К ней относят любые потребности, мотивы и ценности, которые в той или иной степени побуждают человека осуществлять физкультурно-спортивную деятельность [4, 6, 7]. Мы же в структуре целевой ПМЦС физической культуры человека выделяем семь физкультурных потребностей, а именно:

• в физкультурной деятельности;

- в физической подготовленности;

- в двигательных умениях и навыках;

- в физкультурных знаниях;

- в физкультурном мышлении;

- в физкультурной среде;

- в телесности [10].

Очевидно, что уровень сформированности целевой ПМЦС физической культуры определяется степенью актуализации всех ее элементов. Между тем, проведенные нами исследования показали, что из всех физкультурных потребностей, входящих в структуру целевой ПМЦС физической культуры учащихся, наименее всего актуализированы потребности в физкультурных знаниях и физкультурном мышлении [11]. Возможно это связано с тем, что на занятиях по физическому воспитанию практически не применяются интеллектуальные учебные задания, требующие от учащихся использования физкультурных знаний и физкультурного мышления, поскольку внимание в основном уделяется формированию двигательного компонента физической культуры учащихся, т. е. развитию физических качеств и обучению двигательным умениям и навыкам.

Не случайно, что в последнее время многие ученые и специалисты в сфере физического воспитания и спорта уделяют серьезное внимание формированию интеллектуального компонента физической культуры учащихся [1, 2, 5, 9].

В свое время П. Ф. Лесгафт указывал, что физическое воспитание должно быть направлено не только на физическое, но и на умственное развитие учащихся [3]. В этом плане их следует учить анализировать, сравнивать и оценивать технику изучаемых упражнений, выделяя в них главное и второстепенное. Е. С. Полат в целях интеллектуального развития учащихся предлагает использовать современные педагогические технологии, основанные на личностно-ориентированном подходе. Он отмечает, что в процессе обучения самостоятельное приобретение и применение учащимися полученных знаний должно стать приоритетным, а не усвоение уже готовых знаний [8].

Нам представляется, что проблема формирования интеллектуального компонента физической культуры учащихся может быть в значительной степени решена путем актуализации и формиро- вания у них потребностей в физкультурных знаниях и физкультурном мышлении. С этой целью их необходимо включать в интеллектуальную деятельность, предусматривающую выполнение соответствующих учебных заданий.

Следует отметить, что проблема формирования потребностей в физкультурных знаниях и физкультурном мышлении пока еще не получила должного научного изучения. Таким образом, формирование полноценной целевой ПМЦС физической культуры учащихся невозможно без формирования таких ее элементов, как потребности в физкультурных знаниях и физкультурном мышлении.

Противоречие заключается в том, что необходимость формирования потребностей в физкультурных знаниях и физкультурном мышлении не поддерживается соответствующим методическим обеспечением. Учитывая это обстоятельство, нами в рамках педагогической технологии формирования ПМЦС физической культуры была разработана система интеллектуальных учебных заданий, направленных на актуализацию и формирование потребностей в физкультурных знаниях и физкультурном мышлении учащихся второй и третьей ступеней общего среднего образования [12].

Цель исследования - апробация эффективности интеллектуальных учебных заданий (используемых в рамках педагогической технологии), направленных на формирование потребностей в физкультурных знаниях и физкультурном мышлении учащихся.

Методы исследования: анализ и обобщение научно-методической литературы, анкетирование, формирующий педагогический эксперимент, методы математической статистики.

Результаты исследования и их обсуждение. Исследование проводили на базе ГУО «Специализированный лицей при Университете гражданской защиты МЧС Республики Беларусь», продолжительностью один учебный год (с сентября 2017 по май 2018 г.). В нем приняли участие учащиеся лицея МЧС I-IV курсов в количестве 194 человека. Их возраст соответствовал возрасту учащихся 7-10-х классов общеобразовательной школы. Участники были разделены на контрольную (КГ) $(\mathrm{n}=108)$ и экспериментальную (ЭГ) $(\mathrm{n}=86)$ группы.

Учащиеся ЭГ посещали организованные в лицее занятия по интересам, где выполняли интеллектуальные задания. Для каждого курса учащихся ЭГ в неделю было предусмотрено одно такое занятие, продолжительность которого составляла два учебных часа.

В таблице 1 представлено распределение интеллектуальных учебных заданий, направленных на формирование потребностей в физкультурных знаниях (ФЗ) и физкультурном мышлении (ФМ) на занятиях с учащимися ЭГ I курса на период проведения формирующего педагогического эксперимента, всего было проведено 32 занятия. 
Таблица 1 - Распределение интеллектуальных учебных заданий для учащихся экспериментальной группы I курса на период проведения формирующего педагогического эксперимента

\begin{tabular}{|c|c|c|c|}
\hline \multirow{2}{*}{$\begin{array}{c}\text { Занятие } \\
1 \text {-е }\end{array}$} & \multirow{2}{*}{$\begin{array}{l}\text { Четверть } \\
\text { Первая }\end{array}$} & \multicolumn{2}{|c|}{ Интеллектуальное задание } \\
\hline & & $\Phi 3_{1}$ & - \\
\hline $2-e$ & & $\Phi 3_{2}$ & $\Phi \mathrm{M}_{3}$ \\
\hline 3-e & & $\Phi 3_{3}$ & - \\
\hline $4-e$ & & $\Phi 3_{4}$ & - \\
\hline $5-e$ & & - & $\Phi \mathrm{M}_{9}$ \\
\hline $6-e$ & & - & - \\
\hline 7-e & & - & - \\
\hline $8-e$ & Вторая & $\Phi 3_{5}$ & - \\
\hline $9-e$ & & - & $\Phi \mathrm{M}_{1}$ \\
\hline $10-e$ & & $\Phi 3_{10}$ & - \\
\hline $11-e$ & & $\Phi 3_{10}$ & $\Phi M_{10}$ \\
\hline $12-e$ & & - & $\Phi \mathrm{M}_{11}$ \\
\hline $13-e$ & & $\Phi 3_{6}$ & - \\
\hline 14-e & & - & - \\
\hline $15-e$ & Третья & - & $\Phi \mathrm{M}_{2}$ \\
\hline $16-e$ & & - & $\Phi \mathrm{M}_{18}$ \\
\hline $17-\mathrm{e}$ & & - & $\Phi \mathrm{M}_{12}$ \\
\hline $18-e$ & & Ф3 8 & - \\
\hline $19-\mathrm{e}$ & & - & $\Phi \mathrm{M}_{13}$ \\
\hline $20-e$ & & - & $\Phi \mathrm{M}_{23}$ \\
\hline $21-e$ & & $\Phi 3_{9}$ & - \\
\hline $22-e$ & & - & $\Phi \mathrm{M}_{14}$ \\
\hline $23-e$ & & $\Phi 3_{11}$ & - \\
\hline $24-e$ & & - & $\Phi \mathrm{M}_{17}$ \\
\hline $25-e$ & & $\Phi 3_{7}$ & - \\
\hline $26-e$ & Четвертая & - & $\Phi \mathrm{M}_{18}$ \\
\hline $27-e$ & & - & $\Phi \mathrm{M}_{19}$ \\
\hline $28-e$ & & $\Phi 3_{13}$ & - \\
\hline $29-e$ & & - & $\Phi \mathrm{M}_{15}$ \\
\hline $30-e$ & & - & $\Phi \mathrm{M}_{6}$ \\
\hline $31-e$ & & - & $\Phi \mathrm{M}_{18}$ \\
\hline $32-e$ & & - & - \\
\hline
\end{tabular}

Следует указать, что на выполнение интеллектуальных заданий отводилось от 5 до 30 мин занятия, а остальное время учащиеся выполняли предусмотренные педагогической технологией двигательные задания.

Учащиеся КГ также посещали проводимые в лицее различные объединения по интересам, но без использования в них педагогической технологии.

Основным средством формирования потребностей в физкультурных знаниях и физкультурном мышлении выступали интеллектуальные учебные задания, выполняемые преимущественно игровым и соревновательным методами.

Для актуализации потребности в физкультурных знаниях использовались задания, при выполнении которых необходимо было ответить на задаваемые педагогом вопросы, касающиеся физкультурной тематики. Также активно использовались карточкизадания, содержащие вопросы с несколькими вариантами ответов. Примеры заданий, используемых для актуализации потребности в физкультурных знаниях, представлены в таблице 2 .

Задания, преимущественно направленные на актуализацию потребности в физкультурном мышлении, прежде всего предполагали активизацию у учащихся мыследеятельностных операций, таких как анализ, синтез, сравнение, обобщение и др. Примеры заданий, используемых для актуализации потребности в физкультурном мышлении, представлены в таблице 3 .

Для диагностики степени актуализации потребностей в физкультурных знаниях и физкультурном мышлении использовался специально разработанный диагностический инструментарий [10].

Степень актуализации потребностей в физкультурных знаниях и физкультурном мышлении в КГ и ЭГ до и после формирующего эксперимента представлена в таблице 4.

Из таблицы 4 следует, что до начала проведения формирующего эксперимента как в КГ, так и в ЭГ медиана (Ме) степени актуализации потребности в физкультурных знаниях составила 4 балла, а в физкультурном мышлении - 3 балла, статистически значимых отличий обнаружено не было.

По окончании формирующего эксперимента в КГ медиана степени актуализации потребности в физкультурных знаниях и в физкультурном мышлении составила по 3 балла, в ЭГ соответственно 5 и 4 балла. Динамика степени актуализации потребностей в физкультурных знаниях и физкультурном мышлении в КГ и ЭГ представлена в таблице 5 .

Из таблицы 5 следует, что в ЭГ статистически значимо повысились степень актуализации потребности в физкультурных знаниях с 4 до 5 баллов и с 3 до 4 баллов - степень актуализации потребности в физкультурном мышлении.

В КГ степень актуализации потребности в физкультурных знаниях снизилась с 4 до 3 баллов, а степень актуализации потребности в физкультурном мышлении осталась без изменений ( $\mathrm{Me}=3$ балла).

Выводы. Результаты формирующего эксперимента свидетельствуют об эффективности применения (в рамках педагогической технологии формирования ПМЦС физической культуры) интеллектуальных учебных заданий, направленных на организацию потребностей в физкультурных знаниях и физкультурном мышлении учащихся, 
Таблица 2 - Примеры учебных заданий, используемых для актуализации потребности в физкультурных знаниях

\begin{tabular}{|c|c|}
\hline \multicolumn{2}{|r|}{ Задание 1} \\
\hline Цель & Актуализация потребности в физкультурных знаниях \\
\hline Средство & Интеллектуальное упражнение \\
\hline Метод & Соревновательный \\
\hline Содержание & $\begin{array}{l}\text { Учащимся предлагается пройти тест, состоящий из пяти вопросов, связанных с олимпизмом. } \\
\text { Необходимо из предложенных вариантов ответов выбрать верный и подчеркнуть его. За каждый } \\
\text { правильный ответ начисляется один балл. В соответствии с количеством набранных баллов } \\
\text { учащиеся ранжируются (от 1-го до последнего). На выполнение задания отводится } 5 \text { мин. } \\
\text { 1. Кто из белорусских спортсменов стал олимпийским чемпионом по дзюдо на XXVIII Олимпий- } \\
\text { ских играх в Афинах? } \\
\text { а) Магомед Арипгаджиев; б) Виктор Зуев; в) Андрей Рыбаков; г) Игорь Макаров. } \\
\text { 2. Какой девиз Олимпийских игр? } \\
\text { а) быстрее, выше, сильнее; б) быстрее, сильнее, гибче; } \\
\text { в) быстрее, ловчее, сильнее; г) сильнее, умнее, быстрее. } \\
\text { 3. Что символизируют пять олимпийских колец? } \\
\text { а) союз пяти континентов и встречу спортсменов всего мира на Олимпийских играх; } \\
\text { б) битву спортсменов на Олимпийских играх; } \\
\text { в) честность и уважение спортсменов друг к другу во время проведения соревнований; } \\
\text { г) союз всех государств, принимающих участие в Олимпийских играх. } \\
\text { 4. В какой стране зажигается огонь Олимпийских игр? } \\
\text { а) Турция; б) Греция; в) Египет; г) Кипр. } \\
\text { 5. Какой вид спорта не входит в программу Олимпийских игр? } \\
\text { а) биатлон; б) настольный теннис; в) спортивная гимнастика; г) стрельба. }\end{array}$ \\
\hline Способы мотивации & Ранжирование учащихся, словесные поощрения \\
\hline Критерий успешности & Желание знать правильные ответы на вопросы, связанные с олимпийским движением \\
\hline \multicolumn{2}{|r|}{ Задание 2} \\
\hline Цель & Актуализация потребности в физкультурных знаниях \\
\hline Средства & Интеллектуальные упражнения \\
\hline Методы & Соревновательный \\
\hline Содержание & $\begin{array}{l}\text { Учащимся предлагается пройти тест, состоящий из пяти вопросов, касающихся правил и исто- } \\
\text { рии игры в футбол. Необходимо из предложенных вариантов ответов выбрать верный и подчер- } \\
\text { кнуть его. За каждый правильный ответ начисляется один балл. В соответствии с количеством } \\
\text { набранных баллов учащиеся ранжируются (от 1-го до последнего). На выполнение задания отво- } \\
\text { дится } 5 \text { мин. } \\
\text { 1. Сколько минут длится один тайм в футболе? } \\
\text { а) 45; б) } 40 ; \text { в) 35; г) } 50 \text {. } \\
\text { 2. На каком расстоянии от ворот наносится пенальти? } \\
\text { а) } 10 \text { м; б) } 9 \text { м; в) } 11 \text { м; г) } 12 \text { м. } \\
\text { 3. Какая страна считается родиной футбола? } \\
\text { а) Франция; б) Англия; в) Америка; г) Швейцария. } \\
\text { 4. Из каких частей состоит футбольный мяч? } \\
\text { а) покрышка и подкладка; б) покрышка и камера; } \\
\text { в) подкладка и камера; г) покрышка, подкладка, камера. } \\
\text { 5. В какой ситуации мяч будет считаться забитым в ворота? } \\
\text { а) если больше чем на половину пересечет линию ворот; } \\
\text { б) если полностью пересечет линию ворот; } \\
\text { в) если коснется линии ворот; } \\
\text { г) если будет находиться частично на линии ворот и частично за пределами поля. }\end{array}$ \\
\hline Способы мотивации & Ранжирование учащихся \\
\hline Критерий успешности & Желание знать историю и правила игры в футбол \\
\hline \multicolumn{2}{|r|}{ Задание 3} \\
\hline Цель & Актуализация потребности в физкультурных знаниях \\
\hline Средства & Интеллектуальное упражнение \\
\hline Методы & Соревновательный \\
\hline Содержание & $\begin{array}{l}\text { Учащимся предлагается за одну минуту написать как можно больше названий спортивного инвен- } \\
\text { таря и оборудования. Победитель определяется по наибольшему количеству написанных слов }\end{array}$ \\
\hline Способы мотивации & Ранжирование учащихся \\
\hline Критерий успешности & Желание узнать как можно больше названий спортивного инвентаря и оборудования \\
\hline
\end{tabular}




\begin{tabular}{|c|c|}
\hline \multicolumn{2}{|r|}{ Задание 4} \\
\hline Цель & Актуализация потребности в физкультурных знаниях \\
\hline Средства & Интеллектуальные упражнения \\
\hline Методы & Соревновательный \\
\hline Содержание & $\begin{array}{l}\text { Учащимся предлагается составить из несвязанных слов и словосочетаний правильное определе- } \\
\text { ние понятия «осанка». } \\
\text { Осанка - это ... } \\
\text { непринужденно / и голову прямо }{ }^{2} / \text { человека }{ }^{3} / \text { без активного }^{4} / \text { мышц }^{5} / \text { напряжения }^{6} / \\
\text { привычная } 7 \text { держащего }{ }^{8} / \text { поза }^{9} / \text { стоящего }^{10} / \text { туловище }^{11} \\
\text { Победитель определяется по наименьшему времени, затраченному на составление правильного } \\
\text { определения понятия осанки }\end{array}$ \\
\hline Способы мотивации & Ранжирование учащихся \\
\hline Критерий успешности & Желание знать правильное определение понятия «осанка» \\
\hline
\end{tabular}

Таблица 3 - Примеры учебных заданий, используемых для актуализации потребности в фризкультурном мышлении

\begin{tabular}{|c|c|}
\hline \multicolumn{2}{|r|}{ Задание 1} \\
\hline Цель & Актуализация потребности в физкультурном мышлении \\
\hline Средства & Интеллектуальные упражнения \\
\hline Методы & Опрос \\
\hline Содержание & $\begin{array}{l}\text { Педагог предлагает учащимся объяснить смысл следующих пословиц: } \\
\text { - кто не болел, тот здоровью цены не знает; } \\
\text { • не силой дерутся, а уменьем; } \\
\text { - чистота - залог здоровья; } \\
\text { - хочу - половина могу; } \\
\text { - клавное соревновоние - борьба с самим собой; } \\
\text { - самая эффективнего здоровья; } \\
\text { - что ты делаешь - к тому и готовишься. } \\
\text { За правильное объяснение каждой пословицы учащийся получает одно очко. Участники ранжи- } \\
\text { руются в соответствии с количеством набранных очков }\end{array}$ \\
\hline Способы мотивации & Словесные поощрения, ранжирование учащихся \\
\hline Критерий успешности & Желание понимать смысл пословиц и уметь их объяснить \\
\hline \multicolumn{2}{|r|}{ Задание 2} \\
\hline Цель & Актуализация потребности в физкультурном мышлении \\
\hline Средства & Интеллектуальные упражнения \\
\hline Методы & Наблюдение и анализ. Соревновательный метод \\
\hline Содержание & $\begin{array}{l}\text { Учащимся предлагается проанализировать технику выполнения кувырка вперед. } \\
\text { Для этого педагог вызывает одного из учеников и предлагает ему выполнить кувырок вперед. В } \\
\text { это время педагог и остальные учащиеся оценивают его по 10-балльной шкале. При этом уча- } \\
\text { щийся, который продемонстрировал упражнение, должен также оценить себя. Отметки учащие- } \\
\text { ся ставят на листе бумаги и сравнивают с отметкой педагога. Учащиеся, у которых отметка со- } \\
\text { впала с отметкой педагога, получают два очка, те, кто ошибся на один балл, получают одно } \\
\text { очко, на два или более баллов - получают ноль очков. } \\
\text { После оценивания первого учащегося вызывают следующего. Анализ и оценивание техники } \\
\text { выполнения кувырка вперед повторяется пять раз. Победу одерживают учащиеся, которые на- } \\
\text { брали больше всего очков }\end{array}$ \\
\hline Способы мотивации & Оценивание и ранжирование учащихся \\
\hline Критерий успешности & Желание научиться анализировать и правильно оценивать технику выполнения кувырка вперед \\
\hline \multicolumn{2}{|r|}{ Задание 3} \\
\hline Цель & Актуализация потребности в физкультурном мышлении \\
\hline Средства & Весы, перекладина, физические и интеллектуальные упражнения, лист ватмана, авторучка, фломастер \\
\hline Методы & Метод измерения, анализ \\
\hline Содержание & $\begin{array}{l}\text { А. Учащимся предлагается исследовать зависимость между весом и количеством подтягиваний } \\
\text { в висе на перекладине. } \\
\text { Учащиеся измеряют свой вес и выполняют подтягивание в висе максимальное количество по- } \\
\text { вторений. Данные заносятся в протокол. При помощи педагога строится корреляционное поле }\end{array}$ \\
\hline
\end{tabular}




\begin{tabular}{|c|c|}
\hline & $\begin{array}{l}\text { исследуемой зависимости. Учащимся предлагается визуально оценить зависимость между ве- } \\
\text { сом тела и количеством подтягиваний. } \\
\text { Педагог предлагает ответить на вопросы: } \\
\text { 1. Существует ли зависимость между весом тела и количеством подтягиваний? } \\
\text { 2. Какая направленность данной зависимости (чем больше один параметр, тем больше другой } \\
\text { или чем больше один параметр, тем меньше другой)? } \\
\text { 3. Насколько тесная взаимосвязь между весом тела и количеством подтягиваний? } \\
\text { Педагог предлагает учащимся в свободное время самостоятельно поразмышлять над вопросом: } \\
\text { «Как математически определить вид, направленность, зависимость между весом тела и количе- } \\
\text { ством подтягиваний?». } \\
\text { Б. Педагог опрашивает учащихся относительно вопроса о математическом способе определе- } \\
\text { ния вида, направленности, зависимости между весом тела и количеством подтягиваний, кратко } \\
\text { объясняет суть корреляционного анализа, предлагает провести корреляционный анализ зависи- } \\
\text { мости между весом тела и количеством подтягиваний. } \\
\text { Учащиеся вводят в колонки таблицы «ЭксЕЛь» экспериментальные данные (вес тела и ко- } \\
\text { личество подтягиваний). Педагог проводит корреляционный анализ и предлагает учащимся } \\
\text { осмыслить его результаты и указать вид, направленность, зависимость между весом тела и ко- } \\
\text { личеством подтягиваний в висе на перекладине }\end{array}$ \\
\hline Способы мотивации & Получение нового знания, использование словесных поощрений \\
\hline Критерий успешности & Желание узнать о влиянии веса на результат подтягивания в висе на перекладине \\
\hline \multicolumn{2}{|r|}{ Задание 4} \\
\hline Цель & Актуализация потребности в физкультурном мышлении \\
\hline Средства & Интеллектуальные упражнения \\
\hline Методы & Соревновательный метод, методы словесной демонстрации \\
\hline Содержание & $\begin{array}{l}\text { Учащимся предлагается написать небольшое сочинение на тему «Моя физическая культура», ко- } \\
\text { торое оценивается по 10-балльной шкале с учетом правильности, полноты, системности, само- } \\
\text { стоятельности и креативности выполненной работы. } \\
\text { Учащиеся ранжируются в соответствии с количеством набранных баллов }\end{array}$ \\
\hline Способы мотивации & Ранжирование учащихся \\
\hline Критерий успешности & Желание проникнуть в сущность понятия «Физическая культура» \\
\hline \multicolumn{2}{|r|}{ Задание 5} \\
\hline Цель & Актуализация потребности в физкультурном мышлении (в двигательном мышлении) \\
\hline Средства & Интеллектуальные и физические упражнения \\
\hline Методы & Игровой, соревновательный, анализ, синтез, обсуждение \\
\hline Содержание & $\begin{array}{l}\text { Учащихся разделяют на две команды. Им предлагают придумать и по очереди продемонстри- } \\
\text { ровать различные способы перемещения по гимнастическому мату. Учащиеся становятся в две } \\
\text { колонны с каждой стороны гимнастического мата и по очереди показывают способы перемеще- } \\
\text { ния по нему (например, на коленях, кувырком вперед, переворотом боком, прыжками на левой } \\
\text { ноге и т. д.), которые не должны повторяться. После демонстрации способа ученик становится в } \\
\text { конец строя и ждет своей очереди, придумывая новый способ. При этом учащиеся могут сове-- } \\
\text { щаться и коллективно вырабатывать способы решения двигательной задачи. } \\
\text { За каждый продемонстрированный способ решения двигательной задачи команда получает } \\
\text { одно очко. Побеждает команда, набравшая большее количество очков }\end{array}$ \\
\hline Способы мотивации & Использование игрового и соревновательного методов, словесных поощрений \\
\hline Критерий успешности & Желание придумать как можно больше способов решения двигательной задачи \\
\hline \multicolumn{2}{|r|}{ Задание 6} \\
\hline Цель & Актуализация потребности в физкультурном мышлении (в двигательном мышлении) \\
\hline Средства & Интеллектуальные и физические упражнения \\
\hline Методы & Игровой, соревновательный, анализ, синтез, обсуждение \\
\hline Содержание & $\begin{array}{l}\text { Учащихся разделяют на две команды. Им предлагают придумать и по очереди продемонстриро- } \\
\text { вать различные комбинации из трех акробатических упражнений. Каждая последующая комби- } \\
\text { нация должна отличаться от предыдущей. При этом учащиеся могут совещаться и коллективно } \\
\text { вырабатывать способы решения двигательной задачи. } \\
\text { За каждый продемонстрированный способ решения двигательной задачи команда получает } \\
\text { одно очко. Побеждает команда, набравшая большее количество очков }\end{array}$ \\
\hline Способы мотивации & Использование игрового и соревновательного методов, словесных поощрений \\
\hline Критерий успешности & Желание придумать как можно больше комбинаций акробатических упражнений \\
\hline
\end{tabular}


Таблица 4 - Степень актуализации потребностей учащихся в физкультурных знаниях и фризкультурном мышлении до и после формирующего эксперимента

\begin{tabular}{|c|c|c|c|c|}
\hline \multirow{2}{*}{ Потребности } & \multirow{2}{*}{ Группа } & \multirow{2}{*}{$\begin{array}{c}\text { Степень } \\
\text { актуализации (Me) }\end{array}$} & \multicolumn{2}{|c|}{ Достоверность различий по U-критерию Манна-Уитни } \\
\hline & & & P-level & Отличия \\
\hline \multicolumn{5}{|c|}{ До эксперимента } \\
\hline \multirow[t]{2}{*}{ В физкультурных знаниях } & КГ & 4 & 0,591499 & Не существуют ( $p>0,05)$ \\
\hline & ЭГ & 4 & & \\
\hline \multirow[t]{2}{*}{ В физкультурном мышлении } & КГ & 3 & 0,594377 & Не существуют ( $p>0,05)$ \\
\hline & ЭГ & 3 & & \\
\hline \multicolumn{5}{|c|}{ После эксперимента } \\
\hline \multirow[t]{2}{*}{ В физкультурных знаниях } & КГ & 3 & 0,000002 & Существуют $(p<0,05)$ \\
\hline & ЭГ & 5 & & \\
\hline \multirow[t]{2}{*}{ В физкультурном мышлении } & $\mathrm{K \Gamma}$ & 3 & 0,003866 & Существуют $(p<0,05)$ \\
\hline & ЭГ & 4 & & \\
\hline
\end{tabular}

Таблица 5 - Динамика степени актуализации потребностей в физкультурных знаниях и фризкультурном мышлении за время проведения формирующего эксперимента

\begin{tabular}{|c|c|c|c|c|c|c|}
\hline \multirow[b]{2}{*}{ Потребности } & \multirow[b]{2}{*}{ Группа } & \multicolumn{2}{|c|}{ Степень актуализации (Ме) } & \multicolumn{3}{|c|}{ Достоверность различий по критерию Уилкоксона } \\
\hline & & $\begin{array}{l}\text { до эксперимента } \\
\text { (сентябрь 2017) }\end{array}$ & $\begin{array}{c}\text { после } \\
\text { эксперимента } \\
\text { (май 2018) }\end{array}$ & P-level & Отличия & $\begin{array}{c}\text { Направления } \\
\text { сдвигов }\end{array}$ \\
\hline \multirow{2}{*}{$\begin{array}{l}\text { В физкультурных зна- } \\
\text { ниях }\end{array}$} & КГ & 4 & 3 & 0,221199 & Не существуют (p > 0,05) & $\downarrow$ \\
\hline & ЭГ & 4 & 5 & 0,000002 & Существуют (p < 0,05) & $\uparrow$ \\
\hline \multirow{2}{*}{$\begin{array}{l}\text { В физкультурном } \\
\text { мышлении }\end{array}$} & КГ & 3 & 3 & 0,538076 & Не существуют ( $p>0,05)$ & $\downarrow$ \\
\hline & ЭГ & 3 & 4 & 0,000001 & Существуют (p < 0,05) & $\uparrow$ \\
\hline
\end{tabular}

при этом необходимо следовать следующим практическим рекомендациям:

- включать учащихся в различные виды и формы физкультурно-спортивной деятельности;

- на учебных занятиях использовать интеллектуальные учебные задания;

- в процессе физического воспитания учащихся сочетать двигательную деятельность с интеллектуальной;

- в целях повышения учебной активности учащихся использовать систему внешней мотивации их учебной деятельности;
- обеспечивать качественную демонстрацию образцов физкультурных знаний и физкультурного мышления.

Перспективы дальнейших исследований подразумевают разработку интеллектуальных учебных заданий, направленных на формирование потребностей в соревновательных знаниях и мышлении у юных спортсменов с учетом специфики конкретного вида спорта.

Конфликт интересов. Авторы заявляют, что отсутствует какой-либо конфликт интересов.

\section{Література}

1. Бальсевич ВК. Интеллектуальный вектор фризической культуры человека (К проблеме развития фризкультурного знания). Теория и практика фризической культуры. 1991; 7: 37-41.

2. Журкина АЯ. Обучение школьников физической культуре в условиях новых образовательных стандартов. Физ. культура в школе. 2015; 1: 2-8.

3. Лесгафрт ПФ. Руководство по ффизическому образованию детей школьного возраста. Москва: Физкультура и спорт; 1987. 359 с.

4. Лубышева ЛИ. Современный ценностный потенциал фризической культуры и спорта и пути его освоения обществом и личностью. Теория и практика фризической культуры. 1997; 6: 10-15.

5. Лукьяненко ВП. Физическая культура : основы знаний: учеб. пособие. Ставрополь: Изд-во СГУ; 2001.224 с.

6. Масалова ОЮ. Физическая культура: педагогические основы ценностного отношения к здоровью: учеб. пособие. Москва: КноРус; 2012. 183 с. 
7. Матвеев ВС, Свирид АА, Матвеева ЛА. Педагогическая технология формирования мотивационно-ценностного компонента физической культуры личности студентов. Учен. зап. ун-та П. Ф. Лесгафта, 2014; 11: 90-94.

8. Полат ЕС, Бухаркина МЮ, Моисеева МВ, Петров АЕ. Новые педагогические и информационные технологии в системе образования: Учеб. пособие для студ. пед. вузов и системы повыш. квалиф. пед. кадров. Москва: Издательский центр «Академия»; 2002. 272 с.

9. Стародубцева ИВ. Умственное и физическое воспитание: Точки соприкосновения. Вестн. Южно-Уральского гос. ун-та. 2007; 16 (88): 19-21.

10. Старченко ВН, Метелица АН. Структурно-содержательная модель целевой потребностно-мотивационноценностной сферы физической культуры человека и методика ее диагностики Весн. Мазыр. дзярж. пед. ун-та. 2017; 2: $106-113$.

11. Старченко ВН, Метелица АН. Исследование состояния потребностно-мотивационно-ценностной сферы фризической культуры мальчиков, обучающихся в лицее МЧС и средних школах г. Гомеля. Весн. Магілеўс. дзярж. ун-та. 2017; 2: 56-63.

12. Старченко ВН, Метелица АН. Педагогическая технология фрормирования потребностно-мотивационноценностной сферы физической культуры учащихся. Пед. наука и образование. 2018; 2: 42-49.

\section{Literature}

1. Balsevich VK. Intellectual vector of human physical culture (To the issue of physical culture knowledge development). Teoriya i praktika fizkultury. 1991; 7: 37-41.

2. Zhurkina AY. Teaching pupils physical culture under conditions of new education standards. Fizkultura v shkole. 2015; 1: 2-8.

3. Lesgaft PF. Guide for physical education of schoolchildren. - Moscow: Fizkultura i sport; 1987. 359 p.

4. Lubysheva LI. Modern valuable potential of physical culture and sport and ways of its mastering by society and personality. Teoriya i praktika fizkultury. 1997; 6: 10-15.

5. Lukyanenko VP. Physical culture : knowledge bases: teaching guide. Stavropol: Izdatelstvo SGU; 2001.224 p.

6. Masalova OY. Physical culture: pedagogical bases of valuable attitude towards health : teaching guide. Moscow: KnoRus; 2012. 183 p.

7. Matveyev VS, Svirid AA, Matveyeva LA. Pedagogical technology of forming motivation and value-based component of physical culture component of student personality. Uchenyye zapiski universiteta P. F. Lesgafta, 2014; 11: 90-94.

8. Polat ES, Bukharkina MY, Moiseyeva MV, Petrov AE. New pedagogical and information technologies in education system: Teaching guide for students of pedagogical institutions and the system of advanced training. Moscow: Izdatelsky tsentr «Akademiya»; 2002. 272 p.

9. Starodubtseva IV. Intellectual and physical education: Touch points. Vestnik Yuzhno-Uralskogo universiteta. 2007; 16 (88): 19-21.

10. Starchenko VN, Metelitsa AN. Structure containing model of target need-motivation-valuable sphere of human physical culture and methods of its diagnosis. Vestnik Mazyr. derzh. ped. universiteta. 2017; 2: 106-113.

11. Starchenko VN, Metelitsa AN. Study of the state of need-motivation-valuable sphere of physical culture of boys studying in lyceum of the Ministry of Emergency and secondary schools of Gomel. Vestnik Magilev. derzh. universiteta. 2017; 2: 56-63.

12. Starchenko VN, Metelitsa AN. Pedagogical technology of forming need-motivation-valuable sphere of physical culture of students. Pedagogicheskaya nauka i obrazovaniye 2018; 2: 42-49.

Надійшла 21.10.2018

\section{Інформація про авторів}

Метелица Александр Николаевич. metelitsa1985@mail.ru

Старченко Владимир Николаевич Starch@narod.ru

Гомельский государственный университет имени Франциска Скорины, Гомель, Республика Беларусь
About the authors

Metelitsa Aleksandr, metelitsa1985@mail.ru

Starchenko Vladimir Nikolayevich Starch@narod.ru

Francysk Skaryna Gomel State University, Gomel, Republic of Belarus 